\title{
Numerical analysis of the effective stiffness of elastomeric bearing pads under precast beams for the limit load of lateral instability
}

\section{Análise numérica da variação da rigidez efetiva de almofadas elastoméricas sob vigas pré-moldadas para a carga limite de instabilidade lateral}
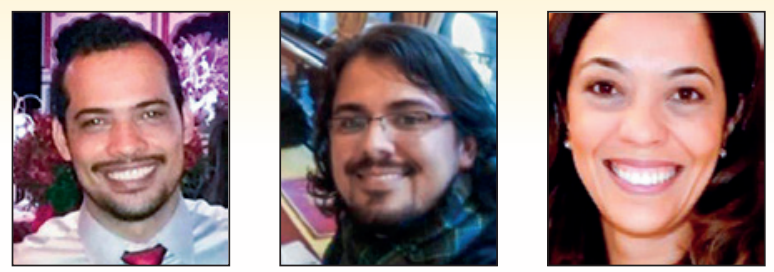

L. C. REIS a

leandroreis.engcivil@gmail.com https://orcid.org/0000-0002-5124-3112

P. A. KRAHL pablokrahl@usp.br https://orcid.org/0000-0002-6172-5481

M. C. V. LIMA a

macris@ufu.br

https://orcid.org/0000-0001-9641-474X

\begin{abstract}
Precast concrete girders on bearing pads are subjected to instability depending on several variables such as span length, initial imperfections and bearing pads behavior. On this paper, numerical models are developed in order to assess the instability limit loads and the rotational stiffnesses of the pads in many combinations of span length, cross section of the girder and lateral sweep. The lift off phenomenon is considered in each analysis by a bearing pad model composed by springs with compression only behavior, with good results in comparison with the experimental values of the technical literature. The increase in spans and initial imperfections causes a decrease in the rollover limit load. The lift off effect is aggravated as the lateral eccentricities increase. In the analyzed combinations, the reduction of the rotational stiffness is about $37 \%$ for the critical situation, which span length about $40 \mathrm{~m}$ and lateral sweep of L/300, with loss of contact between $50 \%$ and $60 \%$.
\end{abstract}

Keywords: lateral instability, rollover, elastomeric bearing pads, precast concrete girders.

\section{Resumo}

Vigas de concreto pré-moldado apoiadas sobre almofadas de apoio estão sujeitas a falhas por instabilidade lateral que dependem de vários fatores, entre eles o vão da viga, as imperfeições iniciais e as condições das almofadas de apoio. Neste trabalho, desenvolveu-se modelos numéricos de vigas sobre almofadas, de forma a avaliar as cargas limite de instabilidade e a rigidez efetiva à rotação das almofadas em várias combinações de vão, seção da viga e excentricidade lateral. O levantamento da viga sobre os apoios é considerado em cada análise por meio de um modelo de almofada composto por molas com comportamento somente à compressão, com resultados satisfatórios comparados a respostas experimentais da literatura técnica. O aumento nos vãos e nas imperfeições iniciais reduzem a força limite de tombamento. O levantamento da viga sobre as almofadas é agravado conforme aumentam-se as excentricidades laterais. Nos casos analisados, a diminuição da rigidez ao giro é em torno de $37 \%$ para a situação mais crítica, com vão L de 40 m e excentricidade de L/300, com perda de contato variando entre $50 \%$ e $60 \%$.

Palavras-chave: instabilidade lateral, tombamento, almofadas de apoio elastoméricas, vigas pré-moldadas. 


\section{Introduction}

There exist various reports concerning the collapse of precast beams, which were simply supported on neoprene bearing pads (OESTERLE et al.[1]; BAIRÁN; CLADERA [2]). The stiffness of the bearing pad, the slenderness of the beam, deformation from thermal effects, shrinkage and creep may go on to influence, in isolation or in a combined manner, the capacity of these structural elements to prevent rollover failures during the construction phase.

Despite the high risk to worker safety and losses caused by this type of collapse, there in fact exist few experimental studies developed on the subject (CONSOLAZIO; HAMILTON; BEERY [3],HURFF; KAHN [4]). Consequently, few numerical studies have been performed to represent the behavior of long beams under rollover failure, when only supported on neoprene bearing pads (KRAHL; CARRAZEDO; EL DEBS [5]; LEE [6]; CARDOSO; LIMA [7]). However, this field of research requires greater investigation in the field of experiment, as well as numerical, in order that recommendations can be established. Highlighted here is that faced with various accidents that have been reported, until the present moment, there does not exist any type of normative code that establishes recommendations for this stage of construction.

In this context, the present study aims at numerically analyzing the variation in effective stiffness of the elastomeric bearing pads, under precast beams, for the limit load of lateral instability. To this end, the length of the beam, the cross section geometry, the effects of initial lateral imperfections (eccentricity), along with the characteristics of the elastomeric bearing pads are all considered as the principal variables.

\section{Numerical analysis in finite elements}

Numerical analyses are performed in order to determine effective stiffness of the interaction between the elastomeric bearing pads and precast beams during rollover phenomenon. The models of bearing pads and beams are validated through experimental studies found in the literature. In addition, parametric analyses are performed for evaluating the behavior of the beam-bearing pad system, considering the variation in geometric parameters, such as span and beam section as well as geometric imperfections.

The numerical analyses developed in this study are performed through the computer program ANSYS, using solid elements for the beams and both solids and springs for the bearing pad.

In the experimental studies reported in the literature, there are indications of rollover failures occurring before cracking in the concrete (HURFF [8], CONSOLAZIO; HAMILTON; BEERY [3]). Therefore, linear elastic behavior for concrete is adopted, for which modelling is performed using solid elements. In order to describe large displacements and rotations that normally occur in very slender elements, nonlinear geometry is considered in the analyses. As a solution to the nonlinear problem, the numerical strategy of Newton-Raphson is considered. In the case of the bearing pads, the hypothesis of possible loss of contact with the beam (lift-off) is considered. The bearing pads are modeled with solid elements supported on springs.

\subsection{Finite element and boundary conditions}

The beam is discretized in high order solid elements (SOLID186) with 20 nodes and three degrees of freedom per node regarding translation. The choice of mesh considered as representative for the development of the study considers the variation in both vertical and lateral displacement in the middle of the span, with a margin of error on the displacements measured at around $0.3 \%$ for refinement of the tested mesh. The modeling of the beam on end support apparatus is developed taking into consideration the symmetry concerning the problem (Figure 1). In the longitudinal direction the beam was divided into 100 elements of approximately $150 \mathrm{~mm}$.

The bearing pad was simulated computationally with solid

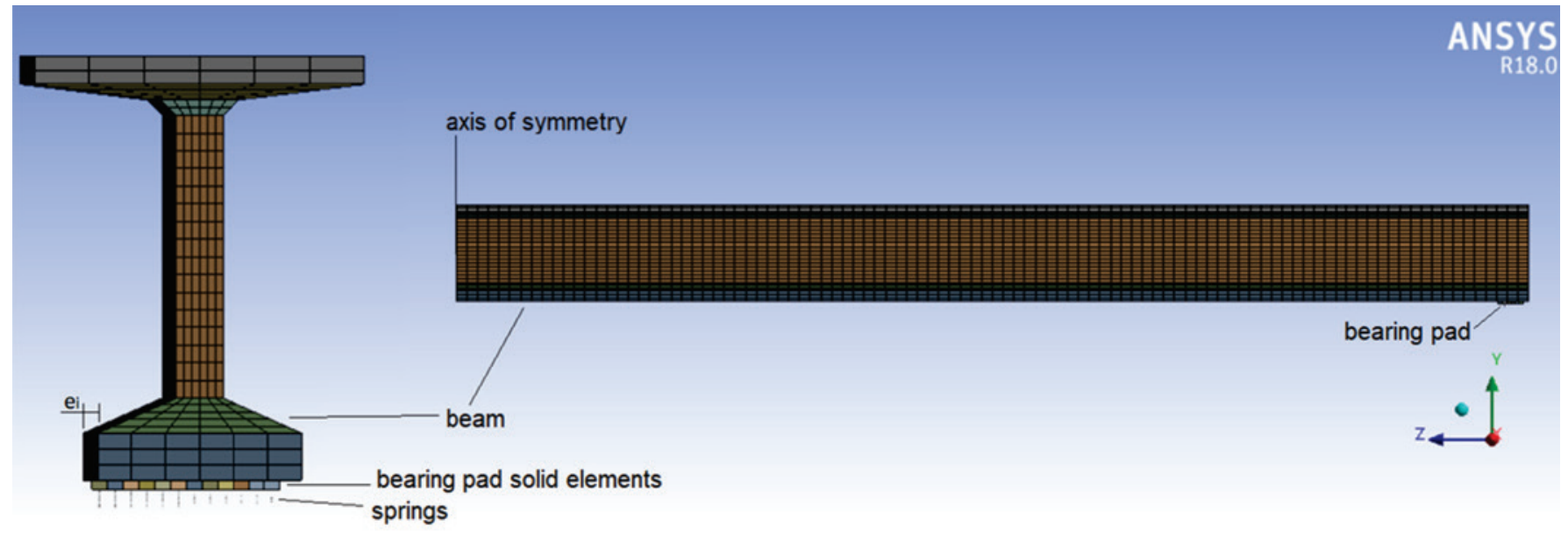

Figure 1

Cross section of the beam on bearing pads and symmetrical longitudinal discretization Source: Authors (2018) 


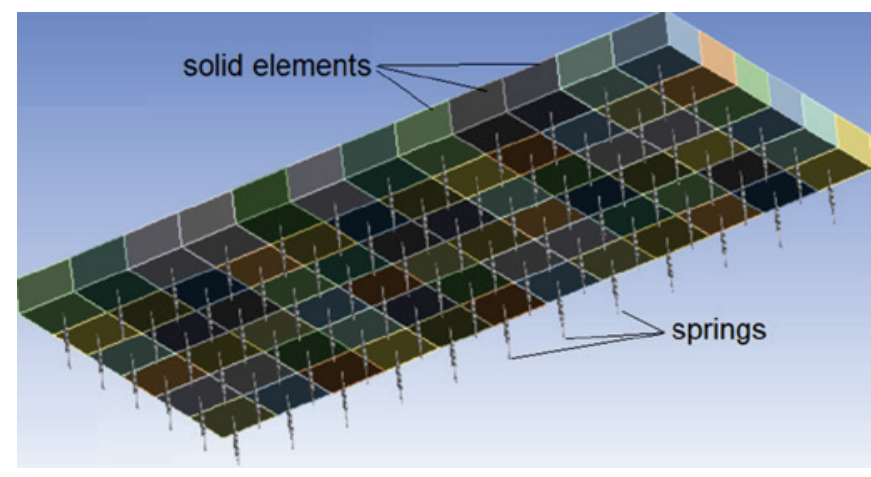

\section{Figure 2}

Model of the bearing pads

Source: Authors (2018)

elements (SOLID186) and springs (COMBIN14) with longitudinal stiffness, linear behavior and exclusive compression, in order to represent the behavior proposed by Harper and Consolazio [9], which is described in Section 2.3 of this study (Figure 2).

\subsection{Applying the load and determining the limit load}

In all the developed analyses, first the self-weight of the beam is applied in 10 loading steps. In cases of calibration, comparison with experimental results in technical literature, a concentrated load is applied to the middle of the span (HURFF [8]) and concentrated loads to the middle thirds (CONSOLAZIO; HAMILTON; BEERY [3]). For the developed parametric analysis, after the application of self-weight (initial situation), the concentrated load is applied to the middle of the span (limit situation) in order to obtain the rollover limit load (Figure 3 ).

The limit load is defined through the applied curve load $\mathrm{x}$ lateral

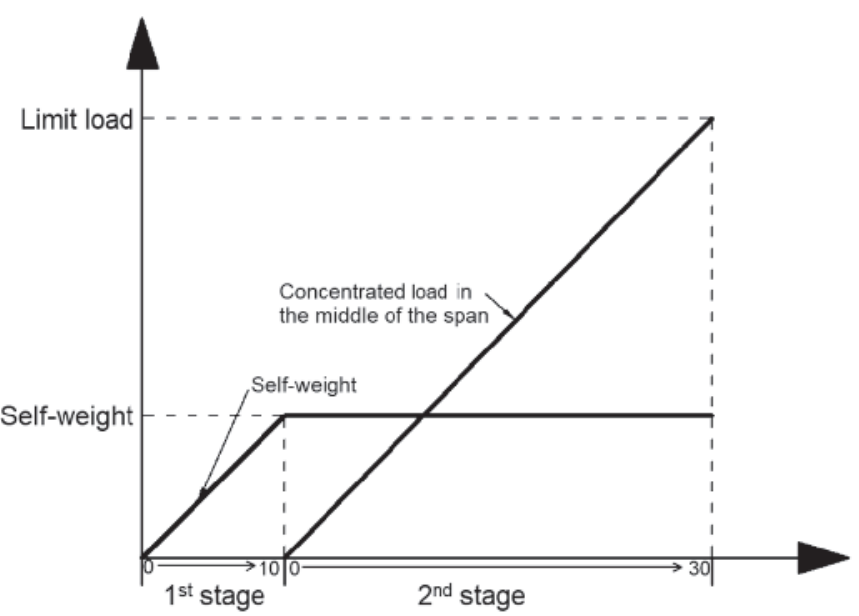

Figure 3

Application scheme for the load in the parametric analyses

Source: Authors (2018) displacement in the middle of the span, according to Consolazio, Hamilton and Beery [3]. Through this criterion, one adopts as the rollover limit load as the point where the inclination of the tangent to the load-displacement curve is $1 / 10$ to the initial stiffness (Figure 4).

\subsection{Modeling of the bearing pads}

In this section, is developed the simulation of the of the bearing pads with dimensions of $609.6 \times 279.4 \mathrm{~mm}$, and a height of 48.4 $\mathrm{mm}$ and 3 internal sheets of steel (type A), and dimensions of $609.6 \times 355.6 \mathrm{~mm}$, with a $65.0 \mathrm{~mm}$ height and 4 internal sheets of steel (type B). In order to analyze the numerical behavior of the bearing pads, beams were modeled as those used in tests by Consolazio, Hamilton and Beery [3] and Hurff [8] supported on bearing pads type $A$ and $B$, respectively.

In the stability analyses, one should know, chiefly, the compression stiffness and the rotation of the bearing pads. For the beam supported on bearing pads, the sinking of the bearing pad depends on the compression stiffness that occurs under the weight of the beam. On the other hand, the rotation of the bearing pad and the lift-off effect of the least compressed border depends on the compression level of the bearing pad itself.

Based on the experimental studies, in order to estimate the rotational stiffness of the bearing pad apparatus, Harper and Consolazio [9] suggest the use of the simplified grillage model, which divides the bearing pad into discrete rectangular regions and models each region with a spring that represents the stiffness contribution for this region. Springs are used that are subject only to compression in order to simulate the lift-off of the least compressed border. The upper nodes of the springs are linked together forming a rigid body, which represents the top surface of the bearing pad.

The variation in stiffness and the only compression behavior of the springs, without traction support reactions, allows in a

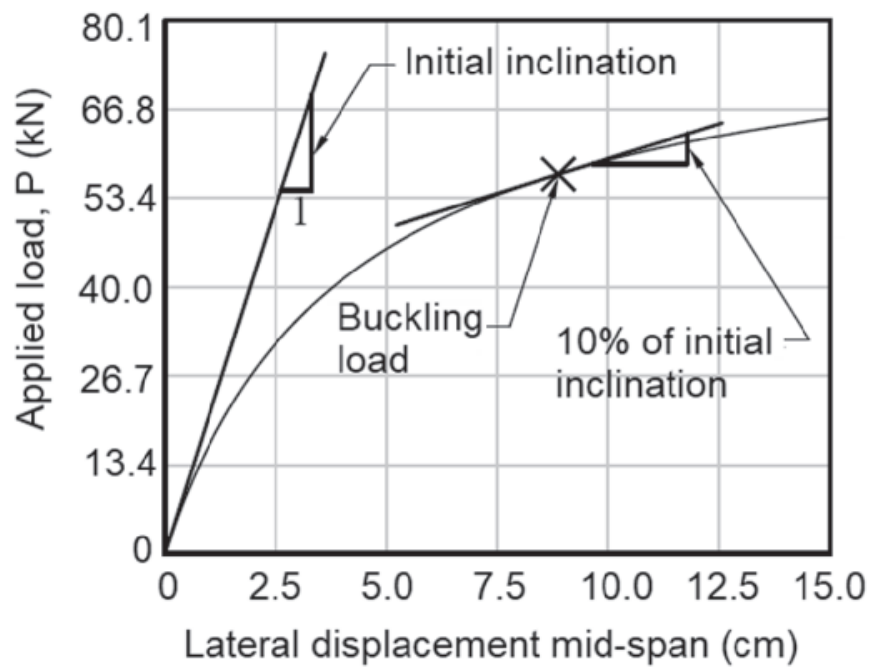

Figure 4

Definition of limit load

Source: Adapted from Consolazio, Hamilton and Beery [3] 


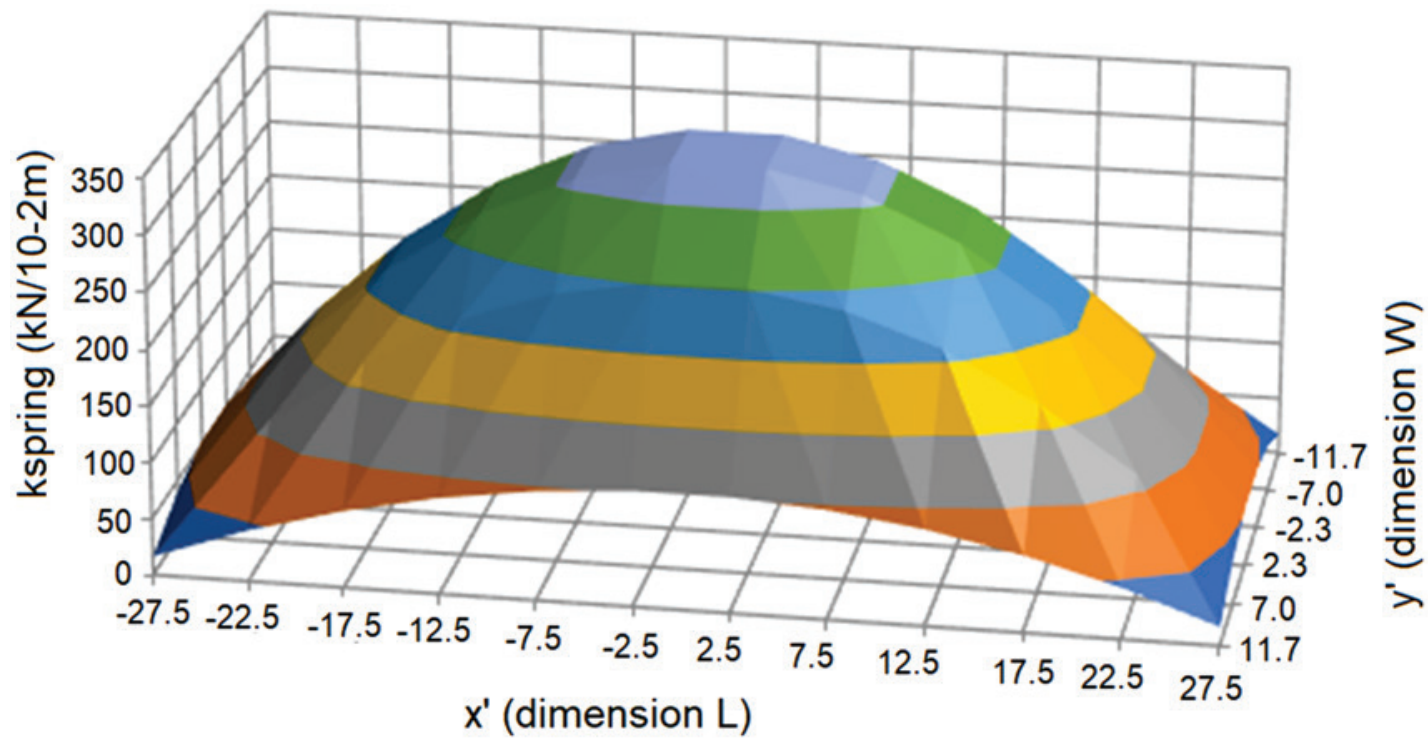

Figure 5

Distribution of stiffness of the springs due to the contribution from the position on the bearing pad Source: Cardoso [10]

simplified manner for the representation of the non-linear behavior of the bearing pad. Figure 5 demonstrates the variation in the stiffness of the spring due to its position on the bearing pad, where the central region of the bearing pad is responsible for absorbing the highest portion of the demand, which is a result of the confinement effect.

In the parametric analyses performed in this study, the bearing pad considered is that tested by Hurff [8], where the compression stiffness was obtained experimentally at a value of $1042 \mathrm{kN} / \mathrm{mm}$. With the compression stiffness of the bearing pad at hand, the longitudinal stiffness is calculated for each spring, which takes into account the stiffness to weight, given by the position of the spring in the region of the bearing pad (Equation 1).

$k_{\text {spring }}\left(\mathrm{x}^{\prime}, \mathrm{y}^{\prime}\right)=A_{\text {regono }} \cdot\left(\frac{k_{\text {pad }}}{A_{\text {pad }}}\right) \cdot\left[1-\left(\mathrm{x}^{\prime}\right)^{2}\right] \cdot\left[1-\left(\mathrm{y}^{\prime}\right)^{2}\right]$

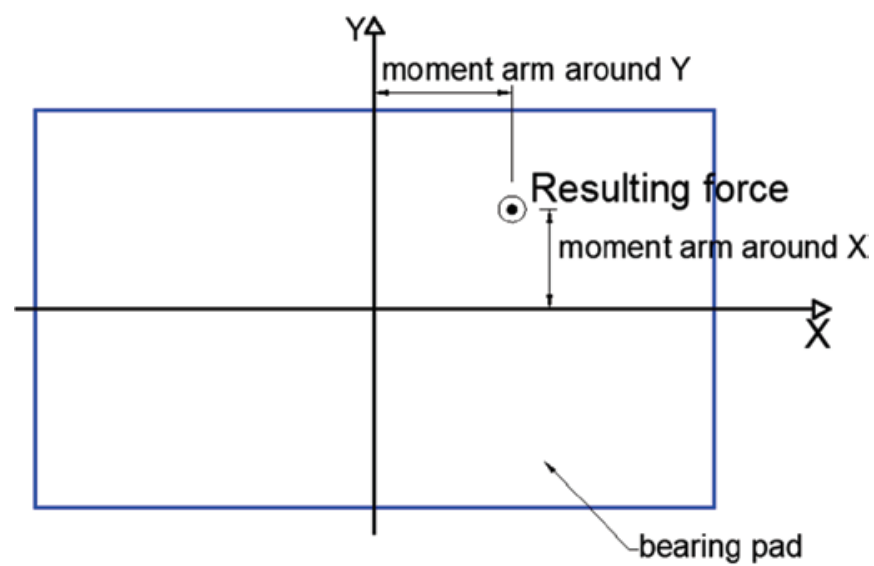

\section{Figure 6}

Scheme for the determining of moments Source: Authors (2018)
Where $k_{\text {spring }}\left(\mathrm{x}^{\prime}, \mathrm{y}^{\prime}\right)$ is the value of the spring stiffness; $A_{\text {region }}$ is the area of the spring region; $k_{p a d}$ is the compression stiffness of the bearing pad and $A_{p a d}$ is the area of bearing pad and x' and y' are the normalized coordinates of the bearing pad.

\section{Calculation of effective stiffness of the bearing pads}

Rotational stiffness is important in the evaluation of lateral instability of the beams, when the only restriction to rotation is given by the bearing pads. Variation analyses to stiffness in the bearing pads are performed, resulting from loss of contact between the beam and pad, while taking into consideration the application of a concentrated load in the middle of the span. Evaluations are also made as to the effect of the increase in initial lateral eccentricity of the beam in the middle of the span, in terms of stiffness variation to bearing pad rotation.

Effective stiffness to rotation is determined by Equation 2, where $K_{\theta}$ is the rotational stiffness of the bearing pad; $M$ is the moment around the axis under consideration; and $\theta$ is the rotation of the bearing pad.

$\kappa_{\theta}=\frac{M}{\theta}$

The moment is determined by multiplying the resulting load (selfweight and concentrated load) on the bearing pad by the eccentricity that results from the non-uniform load of the bearing pad. Figure 6 shows the lever arm moment for determining the moments around the adopted $\mathrm{X}$ and $\mathrm{Y}$ axis. Rotation is determined by the numerical model through dividing the stretching of the springs at two ends by the distance between them. Through the determination of the remaining variables, one calculates the rotational stiffness of the bearing pad. The stiffness associated with lateral stability of the beams refers to rotation around the $Y$ axis. 


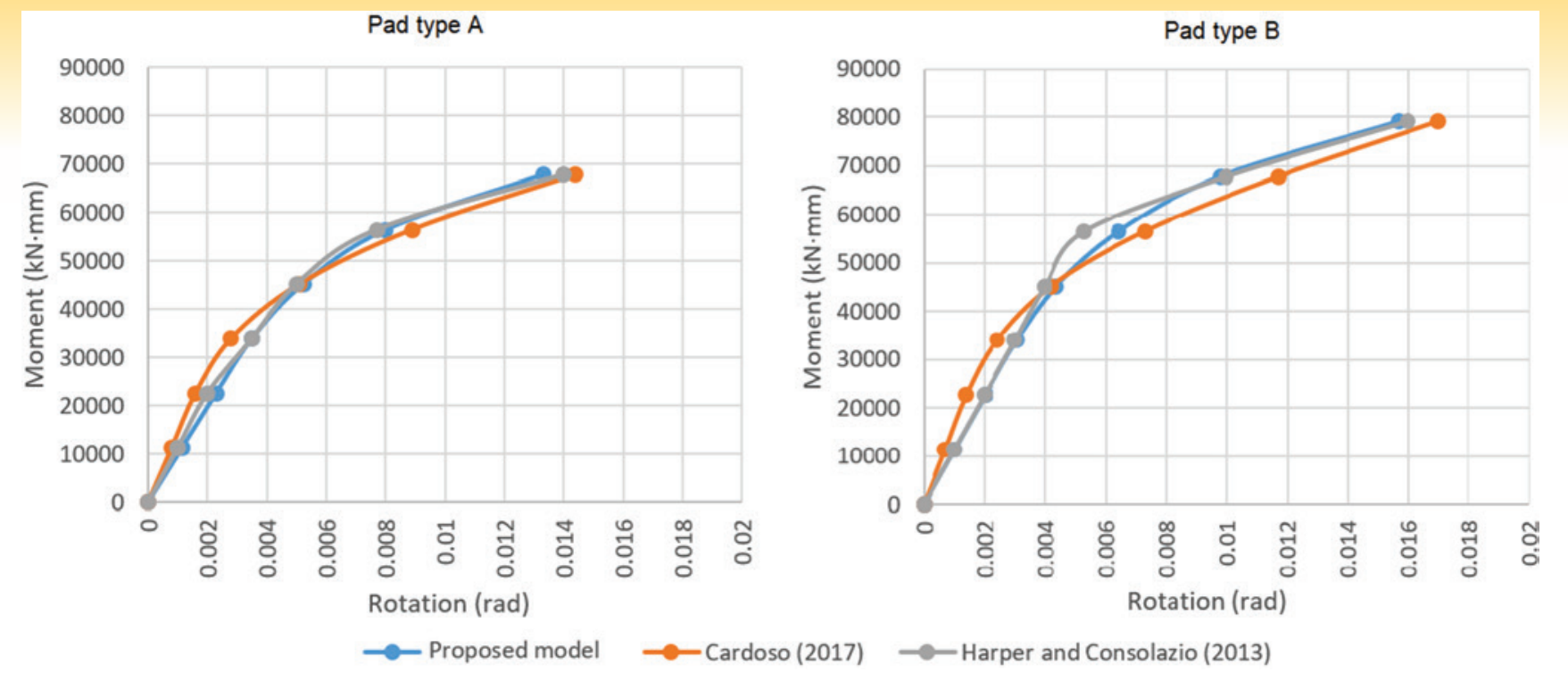

\section{Figure 7}

Comparison of the rotation-moment behavior of bearing pads type $A$ and $B$

Source: Authors (2018)

The position of applied load, regarding the center of the bearing pad, is determined by multiplying the contribution of each spring by its distance in relation to the axis under consideration and, posteriorly, dividing the values obtained by the total resulting load.

\section{Calibration of the numerical model}

In this section, the results for the calibration of the bearing pad model and the model composed of the beam on the bearing pads are presented. These models were validated through experimental and numerical results found in technical literature.

\subsection{Calibration of the bearing pad}

Figure 7 presents the moment curves $\mathrm{x}$ rotation obtained through experiment by Harper and Consolazio [9], these are compared to the results of the model proposed in this study and the numerical results from Cardoso [10].

The proposed model provides results that are very close to curves obtained by the model from Harper and Consolazio [9] as well as the curves from Cardoso [10], remembering that the Harper and Consolazio curves [9] were compared to the experimental curves obtained by the very authors themselves, which validates the curves of the model proposed by the present study.

The main difference between the model proposed in this study with the model from Harper and Consolazio [9] is that in the first solid elements are used for joining the springs and in the second bar elements are used to create this union. The advantage of using solid elements is that the contact between the beam and the bearing pad is completed by the element faces from which they are made, thus avoiding the need to match the bearing pad nodes with the beam nodes in order to link them together. However, the proposed model is capable of numerically representing the loss of contact between the beam and the bearing pad during rollover.

\subsection{Calibration of the beam-bearing pad assembly}

The proposed nonlinear model is calibrated based on the comparison between the two sets of experimental results available in the literature, in the case of beam BT-54 tested by Hurff [8] and beam BT-78 tested by Consolazio, Hamilton and Beery [3].

\subsubsection{Beam tested by Hurff [8]}

The beam tested by Hurff [8] has a $30.5 \mathrm{~m}$ span and is supported on type B elastomeric bearing pads. In the tests, two loads are applied: self-weight of the beam and a concentrated load applied to the center of the span. Figure 8 shows the cross section of the beam.

The total vertical stiffness of the bearing pad provided by Hurff [8] is $1042 \mathrm{kN} / \mathrm{mm}$. As such, the compression stiffness of each component spring of the bearing pad was obtained through Equation [1]. In terms of the concrete, a linear elastic behavior was adopted with an elasticity of $30.8 \mathrm{GPa}$ and a Poisson coefficient of 0.22 .

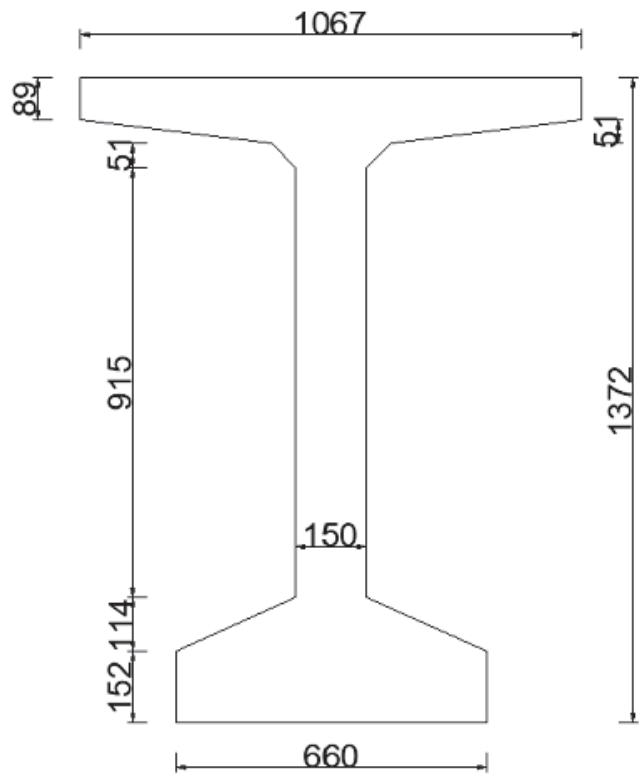

Figure 8

Beam section PCI BT-54 (dimensions in $\mathrm{mm}$ ) Source: Hurff [8] 


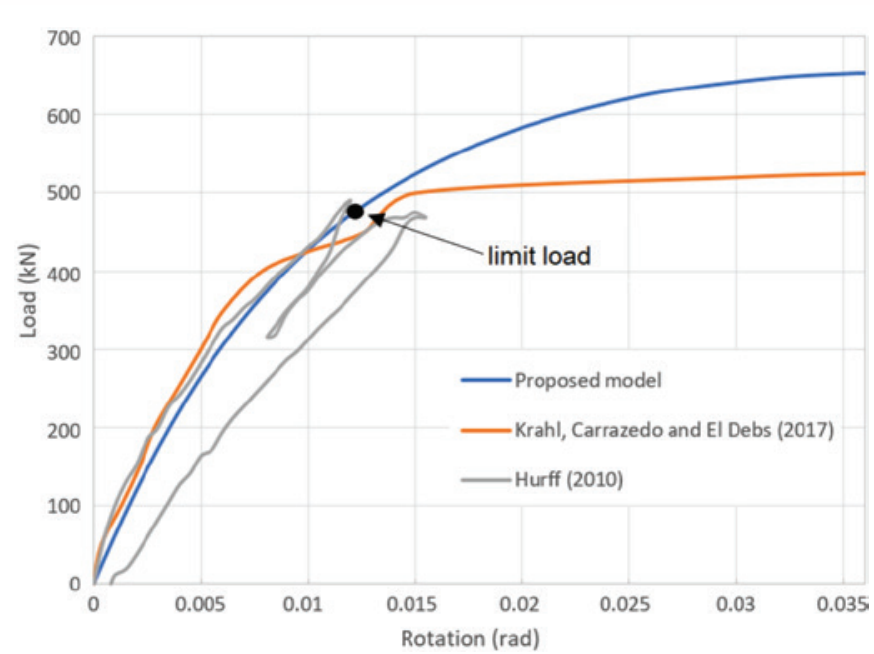

Figure 9

Curve Load $\times$ Beam Rotation BT-54

Source: Authors (2018)

Hurff [8] measured the initial lateral eccentricity of the beam in the middle of the span, with an obtained value of $43.5 \mathrm{~mm}$. Figure 9 presents the comparison of the experimental results from Hurff [8] to the proposed numerical model and the numerical results from Krahl, Carrazedo and El Debs [5].

Through Figure 9, one notes that the initial stiffness of the beamapparatus support systems is very similar. Once the load-displacement curve has been obtained, according to the criterion of Consolazio, Hamilton and Beery [3], one obtains, for the relationship 1/10 of the initial slope (Figure4), a limit load of approximately $484.0 \mathrm{kN}$. This, when compared to the values from Hurff [8] (463.0 kN) and Krahl, Carrazedo and El Debs [5] (503.3 kN), results in differences of $4.5 \%$ and $3.8 \%$, respectively.

Figure 10 shows the loss of contact that occurs with the application of self-weight, before the application of load concentrated in the middle of the span, and the loss of contact through the application of the limit load. One notes that for the initial situation, the loss of contact is $25 \%$, and in the limit situation there was an $11 \%$ increase in lift-off.

\subsubsection{Beam tested by Consolazio, Hamilton and Beery [3]}

The beam tested by Consolazio, Hamilton and Beery [3] is

\section{Self-weight}

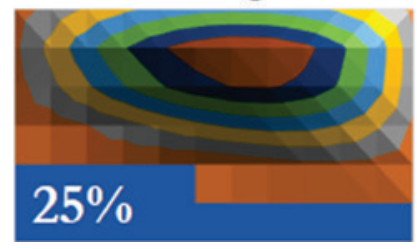

Figure 10

Loss of contact with application of self-weight and the limit load

Source: Authors (2018)

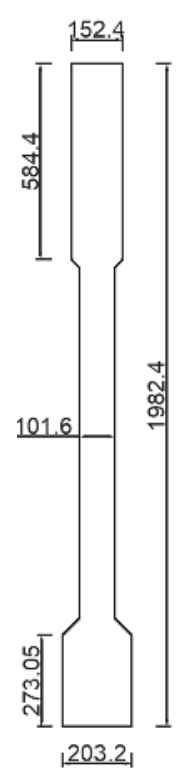

\section{Figure 11}

Beam cross section (dimensions in $\mathrm{mm}$ )

Source: Adapted from Consolazio, Hamilton and Beery [3]

modeled and the values obtained for the instability limit load and lateral displacement in the middle of the span. The beam has a span of $31.11 \mathrm{~m}$ and is supported on type A elastomeric bearing pads. The cross section of the beam is shown in Figure 11.

The applied loads are self-weight and two concentrated loads applied to the thirds of the span. In terms of the concrete, linear elastomeric behavior was adopted, with an elasticity module of 35.4 GPa and a Poisson coefficient of 0.25 .

The curve of applied load $\times$ lateral displacement in the middle of the span presented in Figure 12 contains the numerical answer obtained in this study and the experimental curve from Consolazio, Hamilton and Beery [3].

By considering the limit load as the point where the inclination of the tangent is equal to $1 / 10$ of the initial slope, one obtains a limit load

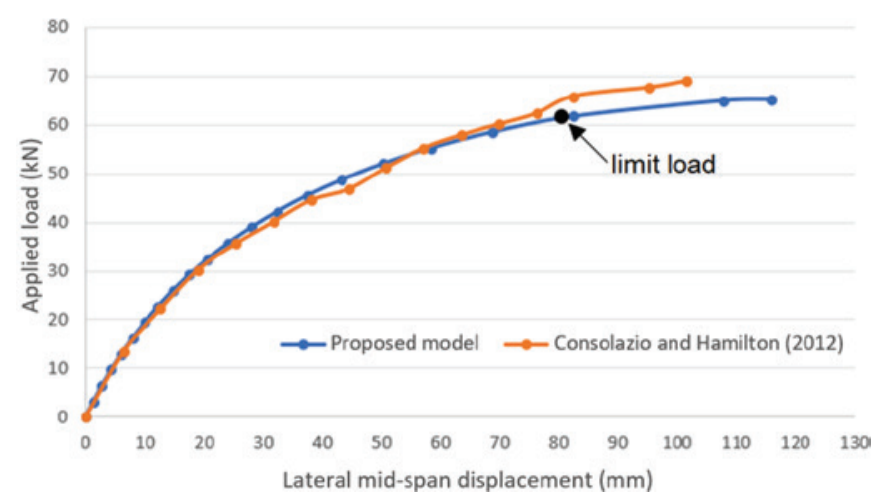

Figure 12

Applied load $\times$ Lateral mid-span displacement Source: Authors (2018) 

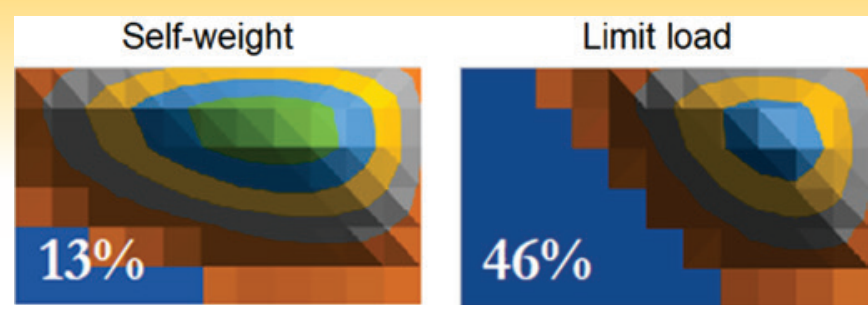

\section{Figure 13}

Loss of contact with application of self-weight and the limit load

Source: Authors (2018)

value of $61.5 \mathrm{kN}$, and where the experimental value of Consolazio, Hamilton and Beery [3] is equal to $68.5 \mathrm{kN}$ (difference of $10.2 \%$ ).

Figure 13 shows the loss of contact in the initial and limit situations. In the initial situation, the loss of contact with the application of selfweight is $13 \%$ and the loss of contact in the limit situation is of $46 \%$, that is, there existed a lift-off increase of $33 \%$.

Due to the elevated slenderness and lift-off, the beam under test

(A)

\section{Span $=25$ meters}

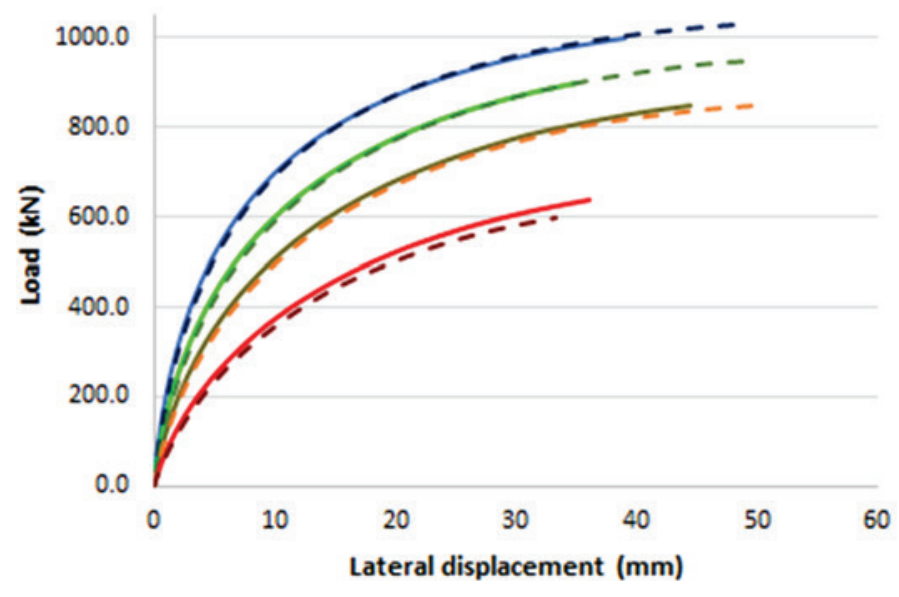

(C)

\section{Span $=35$ meters}

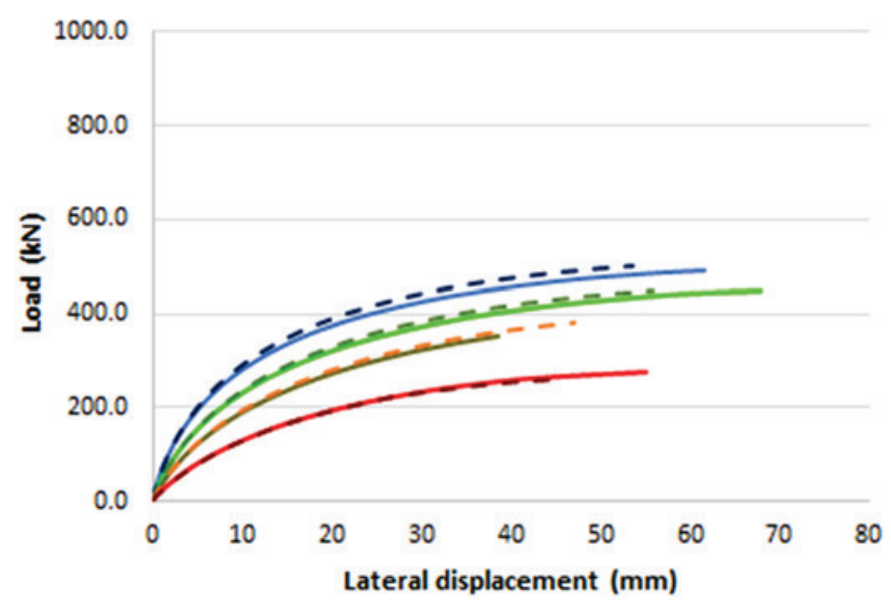

\section{Figure 15}

Load $\times$ Lateral mid-span displacement graph ( $\mathrm{mm}$ ) Source: Authors (2018)

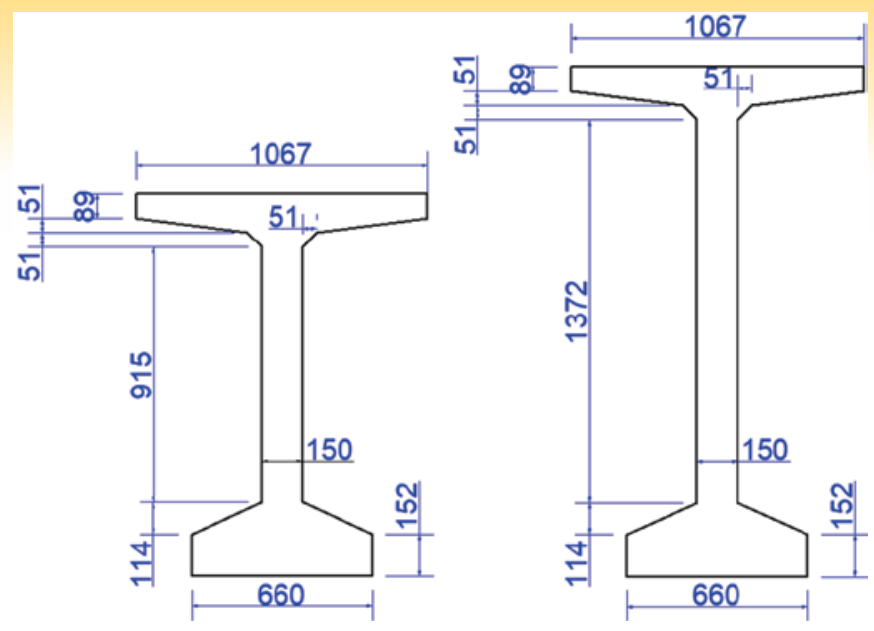

Figure 14

Beam sections BT-54 (left) and BT-72 (right) - dimensions in $\mathrm{mm}$

Source: Authors (2018)

(B)

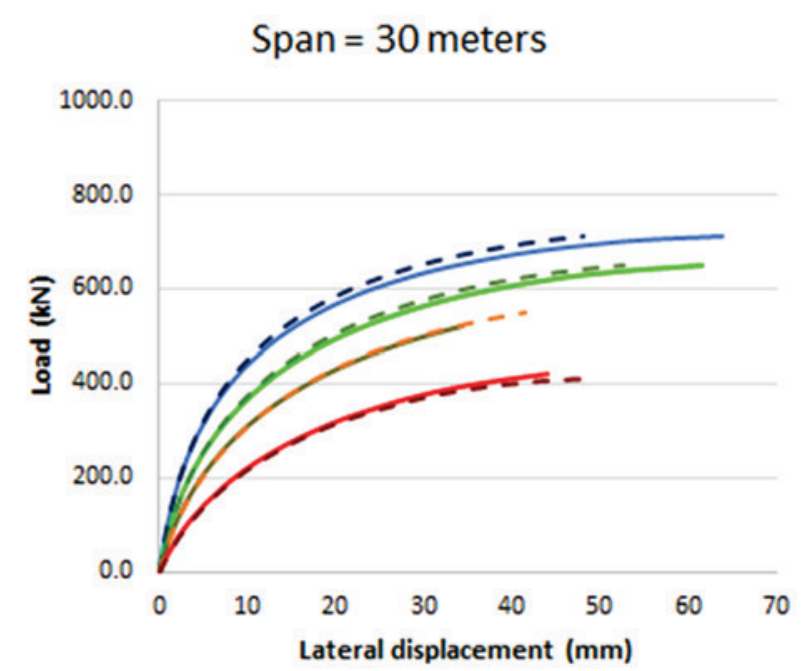

(D)

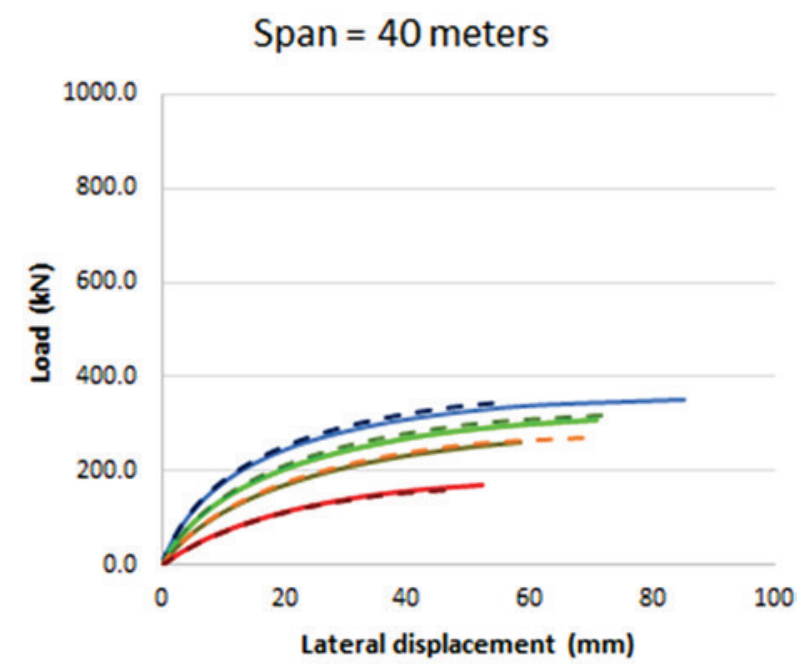




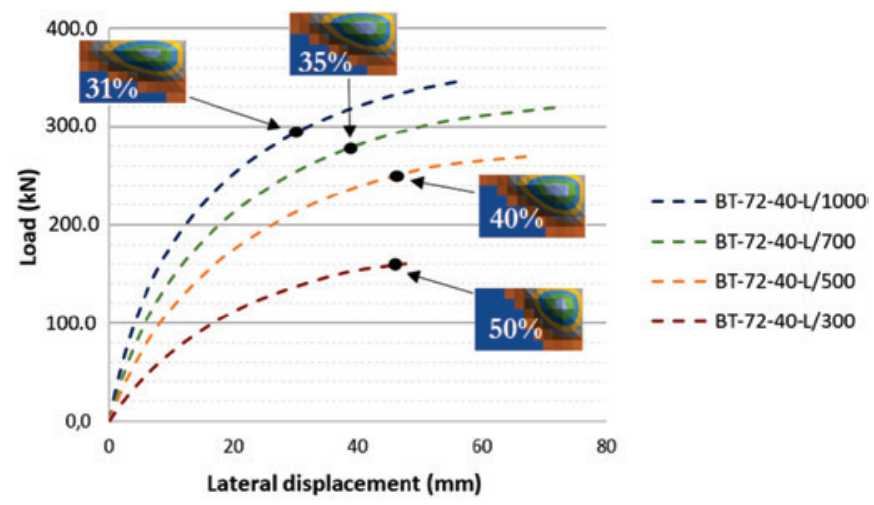

Figure 16

Limit load and lift-off for section BT-72 with a span of $40 \mathrm{~m}$

Source: Authors (2018)

presented from the initial loading a nonlinear behavior. Therefore, the proposed model represented precisely the geometric nonlinearities and loss of contact between the beam and the bearing pad, which occur during rollover.

\section{Parametric analyses}

In order to evaluate the variation in the limit and the influence that initial lateral eccentricity along with length of span exercise over beam lift-off on bearing pads, thirty-two beams were modeled, with 16 beams of the standard section AASHTO BT-54 and 16 of the standard section BT-72. The dimensions of the sections are shown in Figure 14.

The following spans were considered $25,30,35$ and $40 \mathrm{~m}$ and 4 eccentricities (L/1000, L/700, L/500 and L/300, where $L$ is the length of the beam). The form of nomenclature used is BT-5425-L/1000 where BT-54 refers to the beam section, 25 represents the span in meters and $L / 1000$ the value of initial eccentricity, where $L$ is the length of the beam.

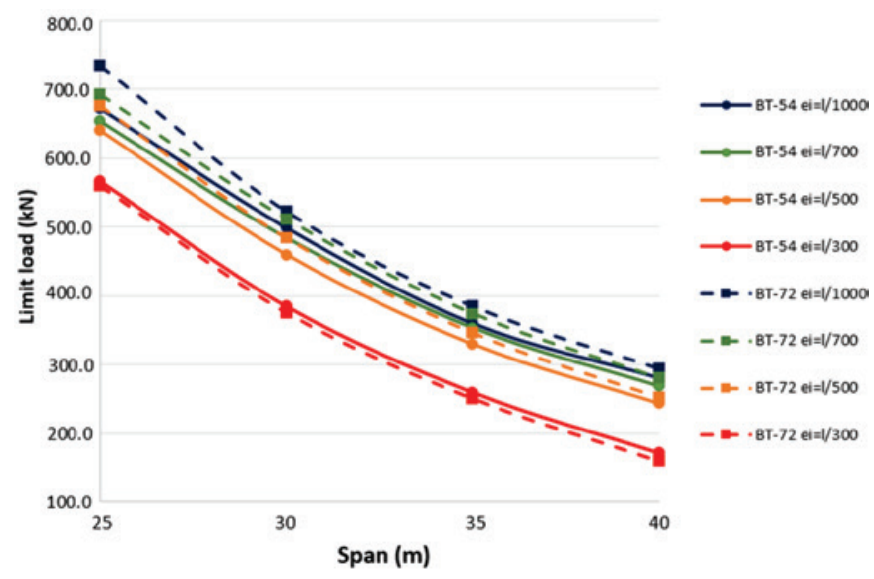

Figure 17

Limit load $\times$ span

Source: Authors (2018)
In the model, the beams are supported on the bearing pads of type B. The total vertical stiffness of the bearing pad used in determining the longitudinal stiffness of each spring component of the bearing pad was that provided by Hurff [8] of $1042 \mathrm{kN} / \mathrm{mm}$. The stiffness associated with each spring was obtained through Equation 1. Regarding the concrete, the same parameters were adopted as in Hurff [8] for the elasticity module and the Poisson coefficient.

\subsection{Lateral displacement and limit load}

For each combination of variables, the curves are presented for Load $\times$ lateral displacement in the middle of the span. From these curves, it is obtained the rollover limit load and the relationship of Limit load $\times$ Considered Span.

Presented also are the resulting loads concerning the bearing pads of each case, along with showing the loss of contact percentage between the beam and the bearing pad for each combination of variables, through a consideration of the two previously described loading situations. Through the resulting load and the loaded area, the compressive stress on the bearing pad for comparison with the limit values from ABNT NBR 9062:2017 [11] is obtained.

Figure 15 shows the graphs for Load $\times$ Lateral displacement in the middle of the span. The curves were divided by span.

Through Figure 15, for the four spans adopted and for the analyzed sections, the change in beam section does not influence significantly lateral displacement in the middle of the span, although the curves for beam BT-72 show a slightly better performance. This occurs due to the fact that the moment of lateral inertia from the two sections does not vary between the beams in any considerable way, since the only difference between the two sections is the height of the beam, more specifically the height of the web, which has little influence on the moment of lateral inertia. Noteworthy here is that as eccentricity increases, greater will be the lateral displacement for the same load applied to the middle of the span.

Figure 16 shows the curves for Load $\times$ Lateral displacement for the section PCI BT-72 and a span of $40 \mathrm{~m}$, highlighting the respective limit loads and loss of contact between the beam and the bearing pads.

The limit load is obtained by the curves for Load $\times$ lateral displacement in the middle of the span, as demonstrated by the inclination of the tangent to the curve. Figure 17 shows the limit load for each section configuration, span and eccentricity of the beams. For the same eccentricity, one notes that the limit load decreased as the span increased. The limit load also decreased as the initial lateral eccentricity increased, where the beams had an eccentricity of L/300, which are much lower limit load values than the rest.

When the limit load $\times$ span curves are compared for the two different sections, with the same span and eccentricity, one notes that the beams with the section BT-72 possess a limit load that is slightly higher when compared to the beams with section BT54. This may be a consequence of the small difference between lateral inertia that exists between the two sections. Another probable cause is the difference in the height of the two sections, as 
Initial situation

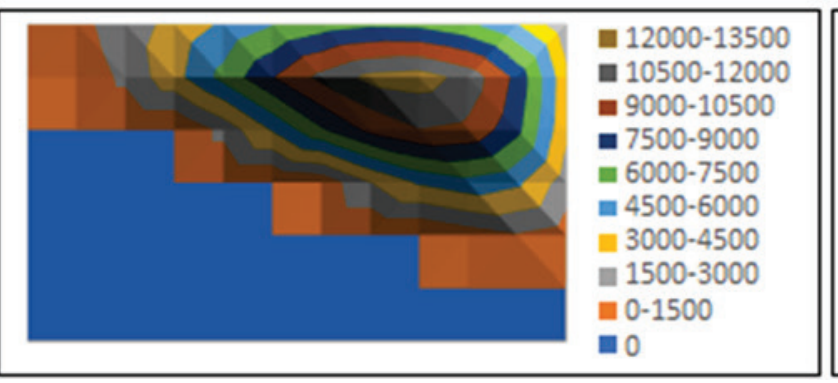

Limit situation

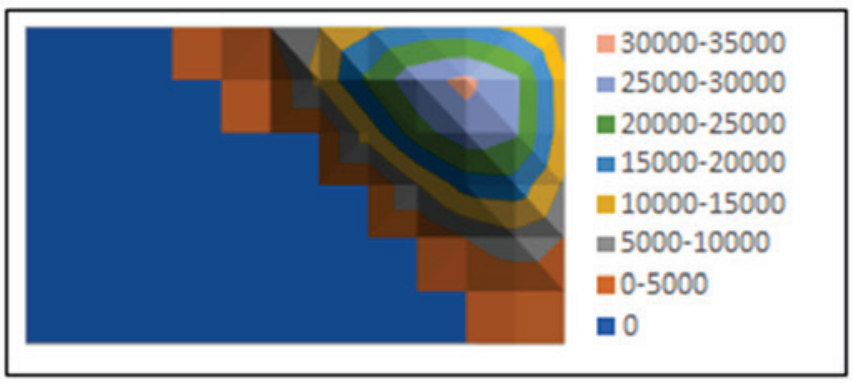

\section{Figure 18}

Lift-off of beam BT-54-40-L/300 onto the pad and reactions on springs ( $N$ )

Source: Authors (2018)

section BT-72 is higher; this may result in a lower lift-off of the beam on the bearing pad.

\subsection{Lift-off of beam from bearing pads}

In the analyses for lateral instability, great importance is given to the evaluation of the occurrence of lift-off of the beam on the bearing pads, as this lift-off is also responsible for the nonlinear behavior of the beams during rollover, as well as the slenderness of the beam, which can result in rotational stiffness of the bearing pad that is lower than necessary for guaranteeing the equilibrium of the beam during this construction stage. In order to evaluate this behavior, the bearing pads were modeled as being a set of solid elements supported on springs. Highlighted here is that the springs in the model work only in compression and therefore, the sprung springs present a reaction equal to zero, representing in this way the region where lift-off of the beam occurs. Lift-off was analyzed in the initial and limit situations, where initial refers to the application of self-weight only, and limit to the application of self-weight and concentrated load in the middle of the span.

Another consequence of loss of contact is that the load applied to the bearing pad is not distributed across the whole area of the bearing pad, which results in greater compressive stress to the loaded areas of the pads, and this load should not surpass the limits imposed by the normative ABNT NBR 9062:2017 [11]. The load applied to the bearing pad refers to self-weight in the initial situation and to self-weight summed together with the limit load of each case. Regarding the limit of compression stress, according to normative ABNT NBR 9062:2017 [11], the maximum stress for the bearing pad, with dimensions $35.6 \times 61.0 \mathrm{~cm}$, is $15.0 \mathrm{MPa}$.

Figure 18 demonstrates the loss of contact for the initial and limit situation for the beam BT-54-40-L/300 and shows the value of the support reactions on a bearing pad, in $\mathrm{N}$.

Through Figure 18, the lift-off causes a significant reduction in loaded area for the beam under analysis. In the initial situation, the loss of contact is $44.44 \%$, and in the limit situation, the loss of contact is of $59.72 \%$. In the initial situation, the compressive stress acting on the loaded area is $1.75 \mathrm{MPa}$ and in the final situation is $4.37 \mathrm{MPa}$. Therefore, the compressive stress does not reach, for any case, the limit imposed by the normative ABNT NBR 9062:2017 [11].

Figure 19 compares loss of contact for beams BT-54 and BT-72, with a $30 \mathrm{~m}$ span and eccentricity of $\mathrm{L} / 300$, for the limit situation. The loss of contact was $47.22 \%$ and $40.28 \%$ for the beams BT-54 and BT-72, respectively.

Table1 shows the loss of contact in both situations, as a percentage, for all beams analyzed. Noteworthy here is that for the same span and same eccentricity, all the beams with section BT-54
Beam BT-54-30-L/300

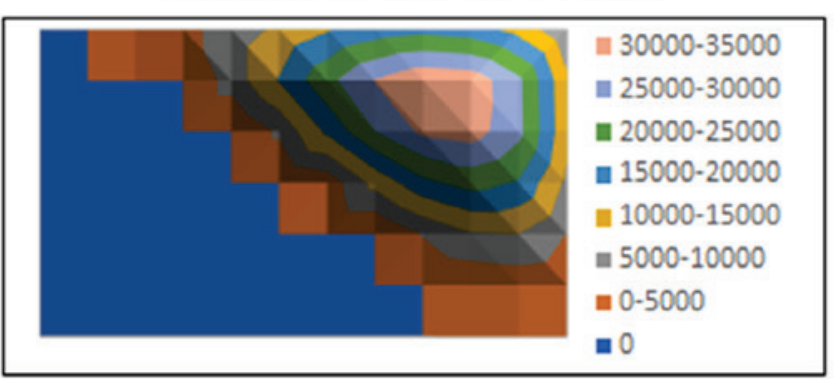

Beam BT-72-30-L/300

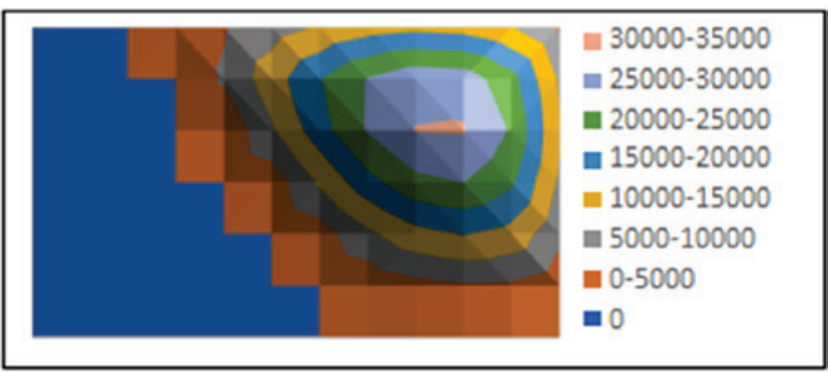

Figure 19

Lift-off of beam BT-54-30-L/300 and BT-72-30-L/300 onto the bearing pad and reaction on springs (N)

Source: Authors (2018) 
Numerical analysis of the effective stiffness of elastomeric bearing pads under precast beams for the limit load of lateral instability

Table 1

Loss of contact in the limit load situation of the beams under analysis

\begin{tabular}{|c|c|c|c|c|c|}
\hline \multirow[t]{2}{*}{ Span (m) } & \multirow[t]{2}{*}{ Eccentricity } & \multicolumn{2}{|c|}{$\begin{array}{c}\text { Initial situation } \\
\text { Loss of contact }(\%)\end{array}$} & \multicolumn{2}{|c|}{$\begin{array}{c}\text { Limit situation } \\
\text { Loss of contact }(\%)\end{array}$} \\
\hline & & BT-54 & BT-72 & BT-54 & BT-72 \\
\hline \multirow{4}{*}{25} & $L / 1000$ & 9.72 & 0.00 & 26.39 & 6.94 \\
\hline & $\mathrm{L} / 700$ & 11.11 & 0.00 & 25.00 & 12.50 \\
\hline & $\mathrm{L} / 500$ & 12.50 & 1.39 & 27.78 & 16.67 \\
\hline & $\mathrm{L} / 300$ & 16.67 & 6.94 & 37.50 & 33.33 \\
\hline \multirow{4}{*}{30} & $\mathrm{~L} / 1000$ & 23.61 & 2.78 & 34.72 & 15.28 \\
\hline & $\mathrm{L} / 700$ & 25.00 & 4.17 & 36.11 & 19.44 \\
\hline & $\mathrm{L} / 500$ & 25.00 & 6.94 & 36.11 & 26.39 \\
\hline & $\mathrm{L} / 300$ & 26.39 & 13.89 & 47.22 & 40.28 \\
\hline \multirow{4}{*}{35} & $\mathrm{~L} / 1000$ & 33.33 & 9.72 & 41.67 & 23.61 \\
\hline & $\mathrm{L} / 700$ & 33.33 & 11.11 & 43.06 & 27.78 \\
\hline & $\mathrm{L} / 500$ & 34.72 & 12.50 & 44.44 & 31.94 \\
\hline & $\mathrm{L} / 300$ & 34.72 & 20.83 & 54.17 & 47.22 \\
\hline \multirow{4}{*}{40} & $\mathrm{~L} / 1000$ & 40.28 & 19.44 & 47.22 & 30.56 \\
\hline & $\mathrm{L} / 700$ & 41.67 & 19.44 & 50.00 & 34.72 \\
\hline & $\mathrm{L} / 500$ & 41.67 & 20.83 & 51.39 & 40.28 \\
\hline & $L / 300$ & 44.44 & 30.56 & 59.72 & 50.00 \\
\hline
\end{tabular}

Source: Authors (2018)

\section{Table 2}

Differences between pad stiffness

\begin{tabular}{|c|c|c|c|c|c|c|}
\hline Beam & $\begin{array}{c}\mathrm{K} \theta \mathrm{y}(\mathrm{pp}) \\
\mathrm{kN} \cdot \mathrm{mm} / \mathrm{rad}\end{array}$ & $\begin{array}{c}\text { K} \theta y \text { (limit) } \\
\mathrm{kN} \cdot \mathrm{mm} / \mathrm{rad}\end{array}$ & $\begin{array}{c}\text { Reduction } \\
\%\end{array}$ & $\begin{array}{c}\mathrm{K} \theta \mathbf{x}(\mathrm{pp}) \\
\mathrm{kN} \cdot \mathrm{mm} / \mathrm{rad}\end{array}$ & $\begin{array}{c}\mathrm{K} \theta \mathrm{x}(\text { limit) } \\
\mathrm{kN} \cdot \mathrm{mm} / \mathrm{rad}\end{array}$ & $\begin{array}{c}\text { Reduction } \\
\%\end{array}$ \\
\hline BT-54-25-L/1000 & $8.54 \mathrm{E}+06$ & $8.10 \mathrm{E}+06$ & 5.18 & $3.12 \mathrm{E}+06$ & $2.98 \mathrm{E}+06$ & 4.52 \\
\hline BT-54-25-L/700 & $8.58 \mathrm{E}+06$ & $7.97 \mathrm{E}+06$ & 7.11 & $3.11 \mathrm{E}+06$ & $2.91 \mathrm{E}+06$ & 6.38 \\
\hline BT-54-25-L/500 & $8.52 \mathrm{E}+06$ & $7.69 \mathrm{E}+06$ & 9.73 & $3.07 E+06$ & $2.77 \mathrm{E}+06$ & 9.97 \\
\hline BT-54-25-L/300 & $8.26 \mathrm{E}+06$ & $6.69 E+06$ & 18.97 & $2.96 \mathrm{E}+06$ & $2.34 \mathrm{E}+06$ & 20.98 \\
\hline BT-54-30-L/1000 & $7.69 \mathrm{E}+06$ & $6.91 E+06$ & 10.16 & $2.86 \mathrm{E}+06$ & $2.55 \mathrm{E}+06$ & 10.94 \\
\hline BT-54-30-L/700 & $7.62 \mathrm{E}+06$ & $6.76 \mathrm{E}+06$ & 11.30 & $2.83 \mathrm{E}+06$ & $2.46 \mathrm{E}+06$ & 13.07 \\
\hline BT-54-30-L/500 & $7.56 \mathrm{E}+06$ & $6.47 \mathrm{E}+06$ & 14.46 & $2.79 E+06$ & $2.32 \mathrm{E}+06$ & 16.66 \\
\hline BT-54-30-L/300 & $7.27 \mathrm{E}+06$ & $5.38 \mathrm{E}+06$ & 26.10 & $2.63 \mathrm{E}+06$ & $1.90 \mathrm{E}+06$ & 27.72 \\
\hline BT-54-35-L/1000 & $6.74 \mathrm{E}+06$ & $6.00 E+06$ & 10.95 & $2.50 \mathrm{E}+06$ & $2.18 \mathrm{E}+06$ & 12.89 \\
\hline BT-54-35-L/700 & $6.68 \mathrm{E}+06$ & $5.81 E+06$ & 13.10 & $2.48 \mathrm{E}+06$ & $2.09 E+06$ & 15.68 \\
\hline BT-54-35-L/500 & $6.57 \mathrm{E}+06$ & $5.47 \mathrm{E}+06$ & 16.71 & $2.43 \mathrm{E}+06$ & $1.95 \mathrm{E}+06$ & 19.84 \\
\hline BT-54-35-L/300 & $6.27 \mathrm{E}+06$ & $4.31 \mathrm{E}+06$ & 31.25 & $2.26 \mathrm{E}+06$ & $1.56 \mathrm{E}+06$ & 31.13 \\
\hline BT-54-40-L/1000 & $5.97 \mathrm{E}+06$ & $5.25 \mathrm{E}+06$ & 12.15 & $2.17 \mathrm{E}+06$ & $1.87 \mathrm{E}+06$ & 13.91 \\
\hline BT-54-40-L/700 & $5.85 \mathrm{E}+06$ & $4.97 \mathrm{E}+06$ & 15.03 & $2.14 \mathrm{E}+06$ & $1.78 \mathrm{E}+06$ & 16.95 \\
\hline BT-54-40-L/500 & $5.76 \mathrm{E}+06$ & $4.51 \mathrm{E}+06$ & 21.65 & $2.10 \mathrm{E}+06$ & $1.64 \mathrm{E}+06$ & 21.77 \\
\hline BT-54-40-L/300 & $5.39 E+06$ & $3.41 E+06$ & 36.84 & $1.93 \mathrm{E}+06$ & $1.28 \mathrm{E}+06$ & 33.61 \\
\hline BT-72-25-L/1000 & $9.03 \mathrm{E}+06$ & $9.55 \mathrm{E}+06$ & -5.81 & $3.19 \mathrm{E}+06$ & $3.40 \mathrm{E}+06$ & -6.29 \\
\hline BT-72-25-L/700 & $9.03 \mathrm{E}+06$ & $9.35 \mathrm{E}+06$ & -3.57 & $3.19 E+06$ & $3.31 E+06$ & -3.71 \\
\hline BT-72-25-L/500 & $9.03 \mathrm{E}+06$ & $8.95 E+06$ & 0.80 & $3.19 E+06$ & $3.13 \mathrm{E}+06$ & 1.90 \\
\hline BT-72-25-L/300 & $8.94 \mathrm{E}+06$ & $7.53 \mathrm{E}+06$ & 15.73 & $3.15 \mathrm{E}+06$ & $2.56 \mathrm{E}+06$ & 18.86 \\
\hline BT-72-30-L/1000 & $9.04 \mathrm{E}+06$ & $8.86 \mathrm{E}+06$ & 1.99 & $3.20 E+06$ & $3.19 E+06$ & 0.51 \\
\hline BT-72-30-L/700 & $8.98 \mathrm{E}+06$ & $8.55 \mathrm{E}+06$ & 4.79 & $3.19 E+06$ & $3.04 \mathrm{E}+06$ & 4.67 \\
\hline BT-72-30-L/500 & $8.90 \mathrm{E}+06$ & $7.99 \mathrm{E}+06$ & 10.18 & $3.16 \mathrm{E}+06$ & $2.79 E+06$ & 11.81 \\
\hline BT-72-30-L/300 & $8.57 \mathrm{E}+06$ & $6.41 E+06$ & 25.24 & $3.01 E+06$ & $2.19 E+06$ & 27.16 \\
\hline BT-72-35-L/1000 & $8.68 \mathrm{E}+06$ & $8.06 \mathrm{E}+06$ & 7.22 & $3.14 \mathrm{E}+06$ & $2.93 \mathrm{E}+06$ & 6.80 \\
\hline BT-72-35-L/700 & $8.61 E+06$ & $7.70 \mathrm{E}+06$ & 10.57 & $3.10 \mathrm{E}+06$ & $2.74 \mathrm{E}+06$ & 11.72 \\
\hline BT-72-35-L/500 & $8.47 \mathrm{E}+06$ & $7.12 \mathrm{E}+06$ & 15.94 & $3.04 \mathrm{E}+06$ & $2.48 \mathrm{E}+06$ & 18.28 \\
\hline BT-72-35-L/300 & $7.92 \mathrm{E}+06$ & $5.38 \mathrm{E}+06$ & 32.17 & $2.78 \mathrm{E}+06$ & $1.89 \mathrm{E}+06$ & 32.25 \\
\hline BT-72-40-L/1000 & $8.05 E+06$ & $7.22 \mathrm{E}+06$ & 10.33 & $2.96 \mathrm{E}+06$ & $2.61 E+06$ & 11.77 \\
\hline BT-72-40-L/700 & $7.96 \mathrm{E}+06$ & $6.82 \mathrm{E}+06$ & 14.28 & $2.92 \mathrm{E}+06$ & $2.42 \mathrm{E}+06$ & 16.91 \\
\hline BT-72-40-L/500 & $7.80 \mathrm{E}+06$ & $6.14 \mathrm{E}+06$ & 21.26 & $2.83 E+06$ & $2.15 \mathrm{E}+06$ & 24.11 \\
\hline BT-72-40-L/300 & $7.13 \mathrm{E}+06$ & $4.51 \mathrm{E}+06$ & 36.65 & $2.49 E+06$ & $1.64 \mathrm{E}+06$ & 34.33 \\
\hline
\end{tabular}

Source: Authors (2018) 


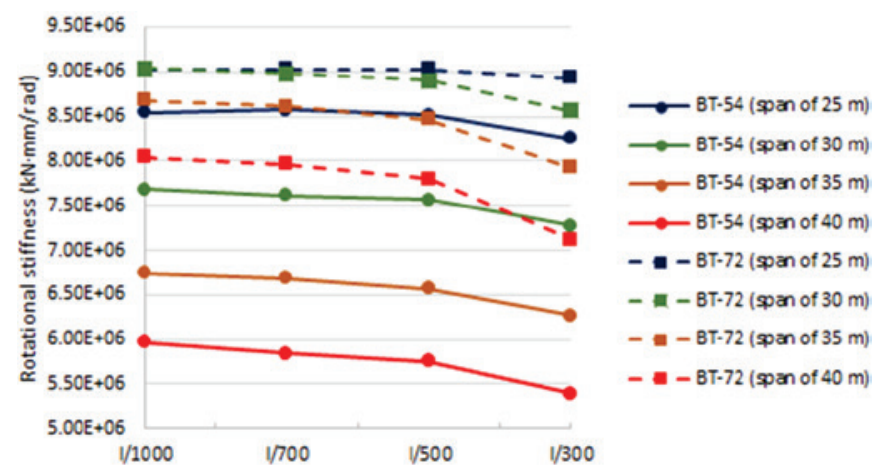

Figure 20

Effective stiffness around $Y \times$ mid-span eccentricity (initial situation)

Source: Authors (2018)

present a higher loss of contact than beams with section BT-72. Note also that for the initial situation only the beams of section BT72 , with a span of $25 \mathrm{~m}$ and eccentricity of $\mathrm{L} / 1000$ and $\mathrm{L} / 700$, did not present lift-off.

\subsection{Effective stiffness of the bearing pads}

Table 2 shows the difference that results from applying the concentrated load in the middle of the span over effective stiffness around the axis $\mathrm{X}$ and $\mathrm{Y}$. On Table 2, the abbreviation "sw" refers to self-weight (initial situation) and "limit" refers to the situation with self-weight summed together with the application of limit load to the middle of the span (limit situation).

By analyzing the values shown on Table 2, the stiffness tends to decrease in accordance with the application of the limit load to the middle of the span. However, for beams BT-72-25-L/1000 and BT-72-25-L/700, there was no reduction, and in fact an increase in rotational stiffness on the bearing pads. It is true that the increase in the initial compression of the bearing pad causes an increase in rotational stiffness. As a result, it is generally understood that the gains from this initial compression are more significant than the

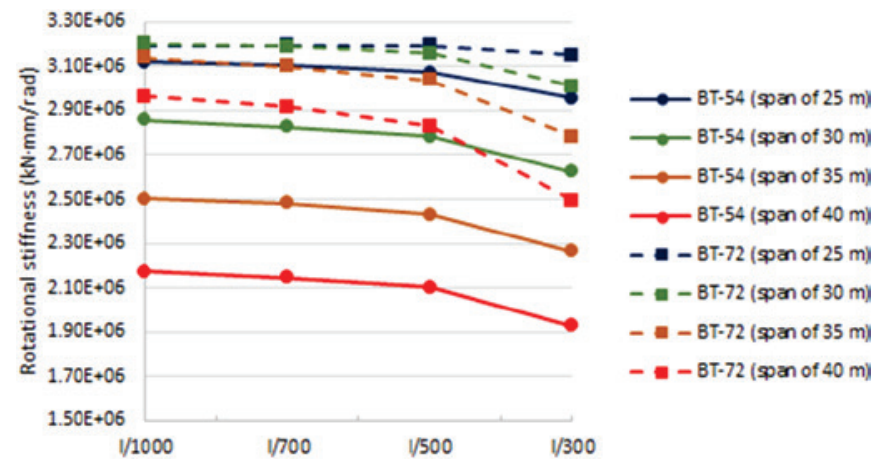

Figure 21

Effective stiffness around $X \times$ mid-span eccentricity (initial situation)

Source: Authors (2018)

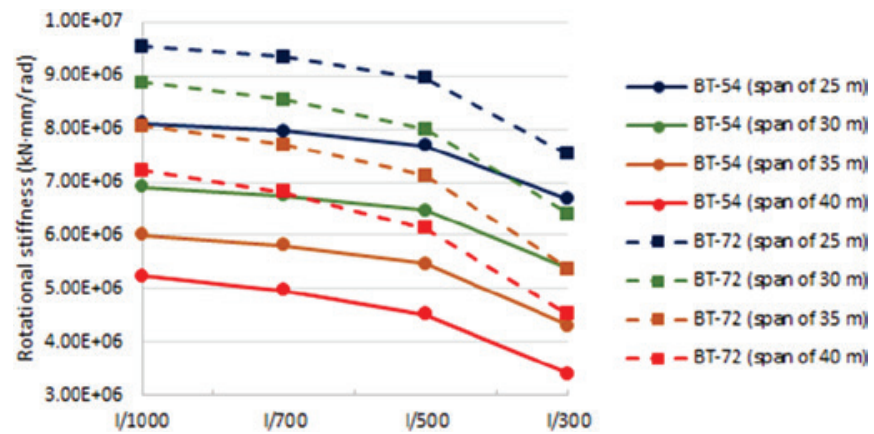

Figure 22

Effective stiffness around $Y \times$ mid-span eccentricity (limit situation)

Source: Authors (2018)

losses caused by the addition of bearing pad rotation due to the load applied in the middle of the span.

Another way of evaluating stiffness is in relation to the increase of eccentricity for the same span and section. To this end, curves are traced for rotational stiffness $\times$ eccentricity in the middle of the span. Figure 20 shows the reduction in effective stiffness in the direction $Y$ and Figure 21 shows the reduction of stiffness in direction $X$, considering the initial situation. The stiffness in $Y$ refers to the lateral bending of the beam, and stiffness in $X$ to the vertical bending of the beam. Figure 22 shows the reduction in stiffness in the direction $\mathrm{Y}$ and Figure 23, in the direction $\mathrm{X}$, for the limit situation.

By analyzing Figure 20 and Figure 21, which refer to the initial state (with the application of self-weight), the stiffness decreases with the increase of eccentricity for all cases. Through a consideration of the stiffness around $Y$, which is that which affects the stability of the beams, one notes that for the span of $25 \mathrm{~m}$, the reduction in stiffness is not so emphasized. However, for the larger spans, mainly for the span of $40 \mathrm{~m}$, the reduction is significant.

The reduction of stiffness around $Y$, for the initial situation, between the beam with eccentricity of $L / 1000$ and the beam with eccentricity of L/300 for BT-54 and BT-72 is $3 \%$ and $1 \%$, respectively.

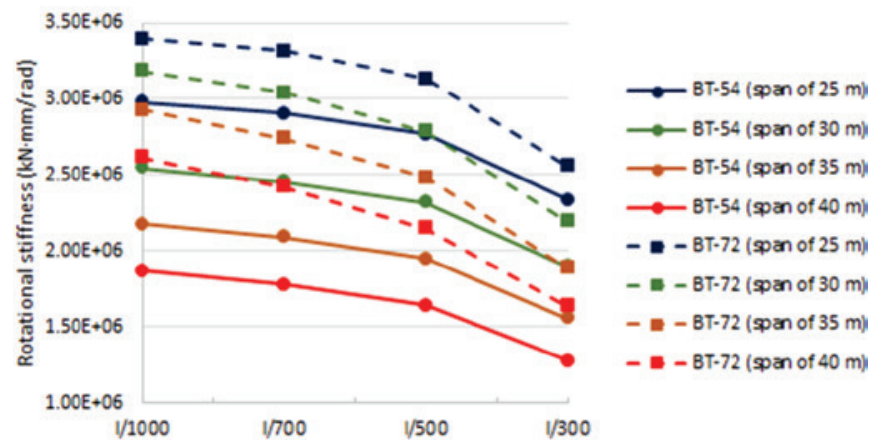

Figure 23

Effective stiffness around $\mathrm{X} \times$ mid-span eccentricity (limit situation)

Source: Authors (2018) 
However, for the span of $40 \mathrm{~m}$, the stiffness around $\mathrm{Y}$ reduces in $10 \%$ for the beam BT-54 and $11 \%$ for BT- 72 .

When comparing the stiffness values, taking into consideration the limit situation, the stiffness reduces considerably for all spans. This difference exists between the initial and limit situation because the moment generated in the limit situation, which considers ownweight plus the load concentrated in the middle of the span, is much greater than the moment generated only by self-weight in the initial situation. Figure 22 and Figure 23 show the stiffness reduction around $Y$ and $X$, respectively, for this limit situation.

The decrease in stiffness around $Y$ for the eccentricity limits under consideration (L/1000 and L/300) for beams BT-54 and BT-72 with a $25 \mathrm{~m}$ span is $17 \%$ and $21 \%$, respectively. For the span of $40 \mathrm{~m}$, the reduction is $35 \%$ for BT-54 and $37 \%$ for BT- 72 .

Therefore, considering only self-weight, one concludes that eccentricity reduces stiffness, in a prominent manner, only for larger spans. This suggests also that this reduction was not greater due to the fact that the moment of lateral inertia possessed an elevated value, as a result of the dimensions of the upper and lower flange tops.

\section{Conclusions}

In a general sense, the present study looked at creating models of beams on elastomeric bearing pads for beam section combinations, spans and eccentricities, as a means to obtain information pertinent to lateral displacements on beams that result from a concentrated load applied to the middle of the span. With this information at hand, the rollover limit load was obtained for each situation, along with an evaluation of the beam lift-off problem, when its rotation on the bearing pad reaches excessive values. In addition, evaluations were made as to the stiffness behavior of the elastomeric bearing pads in the different varieties of combinations. Based on results obtained from parametric studies the following conclusions are drawn:

a) Comparing the two experimental studies: Hurff [8] and Consolazio, Hamilton and Beery [3], the model of beam constituted on solid elements and supported on a simplified pad model, provided adequate values for rotation and lateral displacement in the middle of the span. Regarding the first study, the limit load value obtained was $484.0 \mathrm{kN}$, which when compared to the 463.0 from Hurff [8], results in a difference of $4.5 \%$. Finally, the model of beam from Consolazio, Hamilton and Beery [3], also provided a value close to the limit load $(61.5 \mathrm{kN})$, which differs from the experimental value $(68.5 \mathrm{kN})$ in $10.2 \%$. Therefore, the model is adequate for representing a beam supported on elastomeric bearing pads and that the criterion of the inclination of the tangent to the curve, load $\times$ lateral displacement in the middle of the span, is sufficient to determine the different rollover limit load.

b) The parametric analyses looked to evaluating the variations of the limit load and lift-off of the beams, as the initial imperfections and spans are altered. Regarding the limit load, one notes that the increase in eccentricity and the span cause a reduction of these loads. In terms of beam height, which was considered by using two standard sections of AASHTO (BT-54 and BT-72), the influence that is exercised over lateral instability is not significant, as it is lateral inertia that governs the stability of the beam.

c) Beam lift-off from the bearing pads is of extreme importance in the evaluation of beam stability. In regards to the beams analyzed, even those that had a loss of contact of approximately $50 \%$ between the beam and the bearing pad, the compression stress in the resulting area did not surpass the limit imposed by the Brazilian normative of $15.0 \mathrm{MPa}$.

d) Finally, this study looked to determining the effective stiffness of bearing pads in the initial and limit situations of loading. Noteworthy here is that the rotational stiffness decreased with the increase of eccentricity, and that this reduction arrived at $16 \%$ in some cases, when self-weight was taken into consideration. In the limit situation, the reduction due to eccentricity reached $37 \%$. Highlighted also was that rotational stiffness, after passing the initial situation to the limit situation, decreased in nearly all cases. In this analysis, the increase in rotation of the bearing pad tends to decrease stiffness and the increase in the applied load to the middle of the span tends to cause greater compression on the bearing pad. Therefore, in nearly all cases the increase in rotation was more unfavorable than the increase in the initial compression of the bearing pad due to the increase in applied load.

\section{Acknowledgements}

The authors would like to thank the Coordination for the Improvement of Higher Education Personnel - Brazil (Coordenação de Aperfeiçoamento de Pessoal de Nível Superior - Brasil (CAPES))Financing Code 001 for the Master degree grant and FAPEMIG (Edital Demanda Universal 01/2015Project TEC APQ 00099/15) for the financial support given to this study.

\section{References}

1. Oesterle, R. G.; Sheehan, M. J.; Lotfi, H. R.; Corley, W. G.; Roller, J. J. Investigation of red mountain freeway bridge girder colapse. Arizona Department of Transportation, Bridge Group, Skokie, Illinois. CTL Group Project No. 262291, nov., 2007.

2. Bairán, J. M.; Cladera, A. Collapse of a precast concrete beam for a light roof. Importance of elastomeric bearing pads in the element's stability. Engineering Failure Analysis. Oxford, v. 39, p. 188 - 199, April 2014.

3. Consolazio, G. R.; Hamilton, H. R.; Beery, M. S. Experimental validation of bracing recommendations for long-span concrete girders. Structure Research Report 2012/72909-74040. University of Florida, Gainesville, dec., 2012.

4. Hurff, J. B.; Kanh, L. F. Rollover stability of precast, prestressed concrete bridge girders with flexible bearings. PCl Journal. Chicago, v. 57, n. 12, p. 96 - 107, Fall, 2012.

5. Krahl, P. A.; Carrazedo, R.; El Debs, M. K. Rollover stability of precast concrete beams supported by elastomeric bearing pads. Ibracon structures and materials journal. São Paulo, v. 10, n. 6, p. 1192 - 1204, December 2017.

6. LEE, J.H. Evaluation of the lateral stability of precast beams on an elastic bearing support with a consideration of the initial sweep. Engineering Structures, v. 143, n. 1, p. 101-112, 2017. 
7. Cardoso, M. T. S. A.; Lima, M. C. V. Physical and geometrical non-linear behavior of precast beams on elastomeric supports. Ibracon Structures and Materials Journal. São Paulo, v. 11, n. 7, p. 183 - 202, February 2018.

8. Hurff, J. B. Stability of Precast Prestressed Concrete Bridge Girder Considering Imperfections and Termal Effects. Dissertation. 2010. 483 f. (Degree Doctor of Philosophy) - School of Civil and Environmental Engineering. Georgia Institute of Technology, Georgia, 2010.

9. Harper, Z. S.; Consolazio G. R. Calculation Method for Quantifying Axial and Roll Stiffnesses of Rectangular Steel-Reinforced Elastomeric Bridge Bearing Pads. TransportationResarch Record. Whashington, v. 2331 n. 1 , p. $3-13,2013$

10. CARDOSO, M. T. S. A. Instabilidade lateral de vigas prémoldadas sobre apoios elastoméricos considerando o efeito das imperfeições geométricas. Dissertação (Mestrado), Programa de Pós-Graduação em Engenharia Civil, FECIV, Universidade Federal de Uberlândia, 2017.

11. ASSOCIAÇÃO BRASILEIRA DE NORMAS TÉCNICAS. NBR 9062. Projeto e execução de estruturas de concreto pré-moldado. Rio de Janeiro, 2017. 